International Journal of Current Advanced Research

ISSN: O: 2319-6475, ISSN: P: 2319 - 6505, Impact Factor: SJIF: 5.995

Available Online at www.journalijcar.org

Volume 6; Issue 3; March 2017; Page No. 2673-2675

DOI: http://dx.doi.org/10.24327/ijcar.2017.2675.0073

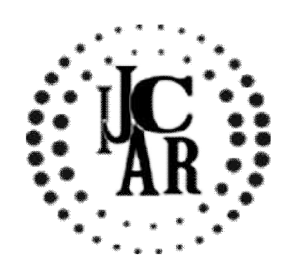

Research Article

\title{
PSYCHOLOGICAL DISTRESS AND COPING STRATEGIES AMONG PATIENTS WITH TEMPOROMANDIBULAR DISORDERS (TMDS)
}

\author{
${ }^{*}$ Kiren $\mathbf{J}^{1}$ and Karpagam $\mathbf{K}^{\mathbf{2}}$ \\ 1,2Department of Anatomy, Saveetha Dental College and Hospitals, 162, Poonamallee High Road, \\ Velappanchavadi Chennai-600077, Tamil Nadu, India.
}

\section{A R T I C L E I N F O}

\section{Article History:}

Received $18^{\text {th }}$ December, 2016

Received in revised form $16^{\text {th }}$ January, 2017

Accepted $26^{\text {th }}$ February, 2017

Published online $28^{\text {th }}$ March, 2017

\section{Key words:}

Psychological distress, coping strategy, temporomandibular disorder.

\begin{abstract}
A B S T R A C T
Background: Temporomandibular disorders (TMDs) comprise a series of dysfunction in the temporomandibular joints. Aim: The aim of the study is to assess the psychological and coping strategies among patients with TMDs. Methods and materials: A descriptive design using survey method was used. The study was conducted among patients with temporomandibular disorders attending the clinic in the selected hospital. Data was collected from 30 participants using a questionnaire with demographic profile and questionnaire related to psychological distress and coping strategies. Descriptive statistics was used for data analysis. Results: There were 16(53.3\%) of them have recently felt that they are ill and felt constantly under strain and bad tempered, 22(73.3\%) have been getting a feeling of tightness or pressure in their heads and lost much sleep over worry recently. With regards to the coping strategies, $19(63.3 \%)$ of them kept themselves busy and occupied, 20(66.7\%) of them are satisfied with the way they completed their work/tasks, $23(76.7 \%)$ were able to enjoy their normal day to day activities. Less than half $13(43.3 \%)$ get involved in any recreational or diversional activities. Conclusion: Interventions to improve the coping is very essential to be implemented to improve the behavioural wellbeing and life style modification of patients with TMDs.
\end{abstract}

Copyright $₫ 2017$ Kiren J and Karpagam K. This is an open access article distributed under the Creative Commons Attribution License, which permits unrestricted use, distribution, and reproduction in any medium, provided the original work is properly cited.

\section{INTRODUCTION}

Temporomandibular disorders (TMDs) comprise a series of dysfunction in the temporomandibular joints and/or functional alterations of the masticatory system, which represent a significant problem in the area of dental health.[1] Temporomandibular disorder (TMD) is a pathology whose signs and symptoms are associated with pain and functional/structural disturbs of the stomatognathic system, especially those related to the temporomandibular joints (TMJ) and masticatory muscles.[2] Carlsson GE stated that about $93 \%$ of the general population shows some kind of temporomandibular disorder, with a range between $5 \%$ and $13 \%$ exhibiting clinically significant symptoms such as pain or severe dysfunction.[3]

A study conducted by Korszun A, indicated that among the patients diagnosed with Temporomandibular disorders, $42 \%$ of them showed high prevalence of "stress associated syndromes". Patients with Temporomandibular disorders underwent stressful public speaking and mental arithmetic tasks. [4] The results of the previous study conducted by Jaspers et al (1993) show those patients with temporomandibular disorders report higher degree of psychological distress. [5]

*Corresponding author: Kiren J

Department of Anatomy, Saveetha Dental College and Hospitals, 162, Poonamallee High Road,

Velappanchavadi Chennai-600077, Tamil Nadu, India.
Several studies have indicated that approximately $60-70 \%$ of people suffer from at least one of the symptoms of temporomandibular disorder (TMD) in their life while only $5 \%$ need treatment. Some of evidence has suggested that myofascialpain; functional somatic syndromes are critical conditions of muscle pain which may be resulted from the psychosocial factors.[6]

\section{Objective}

Patients with temporomandibular disorders complain of orofacial pain, limited jaw opening, and clicking or popping sounds. Although pain is generally the defining characteristics of TMD, patients often report marked degrees of stress and interference in daily life. Hence, this study aims to assess the psychological Distress and Coping Strategies among Patients with Temporomandibular Disorders (TMDs).

\section{MATERIALS AND METHODS}

A descriptive design using survey method was used to assess the psychological distress and coping strategies among patients with Temporomandibular disorders. Subjects were Indians including men and women with temporomandibular disorders. Convenient sampling technique was used to select the participants. Data was collected using a questionnaire which consists of demographic data (Age, Gender and Educational status) and questionnaire related to psychological 
distress and coping strategies. In this survey, a total of 30 subjects participated. Descriptive statistics was used for data analysis. The results were analysed and presented in tables and figures. Data was obtained from the subjects who volunteered to participate in this study.The study was approved by the Institutional Review Board. Informed consent was obtained from the participants before the data collection.

\section{RESULTS}

The demographic data is shown in Figure 1,2 and 3. The results of the demographic profile show that a majority of the participants were above 50 years old $28(26.7 \%)$. There were $16(53.3 \%)$ males and $14(46.7 \%)$ females who participated in this study. Most of them 22(73.3\%) have completed their high school or below.

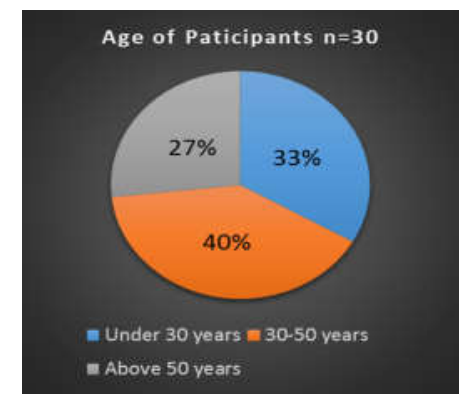

Figure 1 Age of participants $(n=30)$

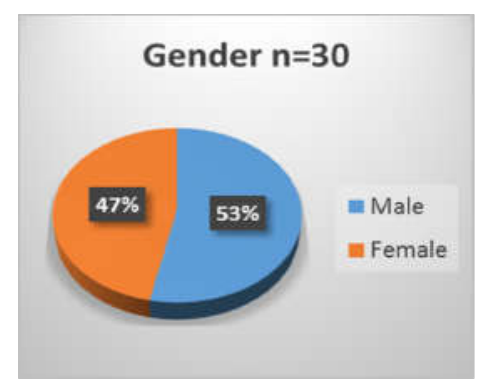

Figure 2 Gender of participants $(n=30)$

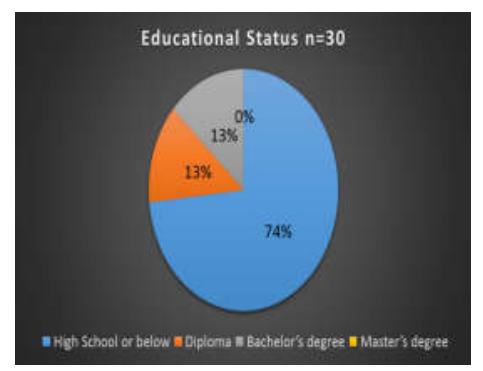

Figure 3 Educational status of participants $(n=30)$
Table 1 shows the results of the psychological distress and coping strategies questionnaire shows that $16(53.3 \%)$ of them have recently felt that they are ill. A highest number of them $22(73.3 \%)$ have been getting a feeling of tightness or pressure in their heads and lost much sleep over worry recently. More than half of them 16(53.3\%) felt constantly under strain and bad tempered. With regards to the coping strategies, $19(63.3 \%)$ of them kept themselves busy and occupied, 20(66.7\%) of them are satisfied with the way they completed their work/tasks, 23(76.7\%) were able to enjoy their normal day to day activities. Whereas, a majority of them $24(80 \%)$ feel worthless and $25(83.3 \%)$ of them feel hopeless. There were $21(70 \%)$ of them who were able to seek social support in times of trouble and worries. The numbers of subjects who get involved in any recreational or diversional activities are less than half $13(43.3 \%)$. More than half of them $19(63.3 \%)$ have the practice of doing some form of exercises. About $20(66.7 \%)$ of them maintain a humorous and positive attitude.

\section{DISCUSSION}

Temporomandibular disorders (TMD) represent a group of orofacial pain conditions that are highly prevalent in the population and are associated with considerable morbidity. Numerous cross-sectional studies demonstrate that people with chronic pain conditions show greater levels of psychological distress, environmental stress, catastrophizing, and somatic symptoms compared with pain-free controls.[7] Rollman GB and Gillespie JM(2000)stated that although pain is generally the defining characteristic of TMD, patients often report marked degrees of stress and interference in daily life.[8]

Although the study results shows that 23(76.7\%) were able to enjoy their normal day to day activities, a majority of them $24(80 \%)$ feel worthless and $25(83.3 \%)$ of them feel hopeless. This shows that the participants are undergoing some form of psychological distress. Only 13(43.3\%) of subjects get involved in some form of recreational or diversional activities, which shows that their coping strategies are very limited.The results from a study conducted byTurner JA in 2001, suggests that for patients with moderate or high levels of TMD pain and dysfunction, beliefs about pain play an important role in physical and psychosocial functioning.[9]

The study results of this study are similar to the findings of the study conducted by Jaspers et al, in the study on Strategies for coping with pain and psychological distress associated

Table 1 Psychological distress and coping strategies among participants.

\begin{tabular}{ccc}
\hline Psychological distress and coping strategies & Yes (\%) & No (\%) \\
\hline 1. Have you recently felt that you are ill? & $16(53.3 \%)$ & $14(46.7 \%)$ \\
2. Have you been getting a feeling of tightness or pressure in your head? & $22(73.3 \%)$ & $8(26.7 \%)$ \\
3. Have you lost much sleep over worry recently? & $22(73.3 \%)$ & $8(26.7 \%)$ \\
4. Do you feel constantly under strain and bad tempered? & $16(53.3 \%)$ & $14(46.7 \%)$ \\
5. Are you getting scared or panicky for no good reason recently? & $5(50.0 \%)$ & $15(50.0 \%)$ \\
6. Are you feeling nervous all the time? & $7(23.3 \%)$ & $23(76.7 \%)$ \\
7. Do you keep yourself busy and occupied? & $19(63.3 \%)$ & $11(36.7 \%)$ \\
8. Are you satisfied with the way you complete your work/tasks? & $20(66.7 \%)$ & $10(33.3 \%)$ \\
9. Are you able to enjoy your normal day to day activities? & $23(76.7 \%)$ & $7(23.3 \%)$ \\
10. Have you been thinking yourself as a worthless person? & $6(20.0 \%)$ & $24(80.0 \%)$ \\
11. Do you feel that life is entirely hopeless? & $-16.70 \%$ & $25(83.3 \%)$ \\
12. Do you seek social support in times of trouble and worries? & $21(70.0 \%)$ & $9(30.0 \%)$ \\
13. Do you get involved in any recreational or diversional activities? & $13(43.3 \%)$ & $17(56.7 \%)$ \\
14. Do you have the practice of doing any form of exercise? & $19(63.3 \%)$ & $11(36.7 \%)$ \\
15. Do you maintain a humorous and positive attitude? & $20(66.7 \%)$ & $10(33.3 \%)$ \\
\hline
\end{tabular}


with temporomandibular joint osteoarthrosis and internal derangement, which shows that psychological distress and pain severity were low, and there was little interference by pain with daily life. While none of the coping strategies were frequently used

\section{CONCLUSION}

The study results show that patients suffer from some kind of psychological distress and unable to cope with the disorder. Interventions to improve the coping are very essential to be implemented to improve the behavioural well-being and life style modification of patients with temporomandibular disorders. AuerbachSM (2001) and authors concluded in their study that psychological factors play a more pronounced role when pain is of muscular origin. Promising behavioural interventions are available for TMD patients in whom psychological factors appear to be playing a significant role.[10]

\section{Acknowledgement}

The authors wish to thank Saveetha Dental College and hospital for the approval and permission to conduct the study. The management and the head of the department is thanked for their continuous support throughout the conduct of the study. The subjects are highly appreciated for the participation.

\section{References}

1. Maite F, Yolanda A, José G, Estrella D, Rafael P, Jose Vincente B. Psychological variables and temporomandibular disorders: Distress, coping,and personality. Oral Surg Oral Med Oral Pathol Oral Radiol2004; 98:153-60.

2. WilkensAurélioBuarque e Silva, Frederico Andrade e Silva, Milene de Oliveira, Silvia Maria Anselmo. Evaluation of the psychological factorsand symptoms of pain in patients with temporomandibular disorder. RSBO 2012; 9:50-5.
3. CarlssonGE. Epidemiology and treatment need for temporomandibular disorders. J Orofac Pain 1999; 13:232-7.

4. Korszun A, Emily P, Mark D, Cary E, Leslie C. The relationship between temporomandibular disorders and stress associated syndromes. Oral Surg Oral Med Oral Pathol Oral RadiolEndod 1998; 86:416-20.

5. Jaspers et al. Strategies for Coping with Pain and Psychological Distress Associated with Temporomandibular Joint Osteoarthrosis and Internal Derangement. The Clinical Journal of Pain 1993; 9: 94-103.

6. 6 Al-Havaz A, Safari S, Mohammadpour N, Kheirkhah F, Motalleb-Nezhad M, Arian M. Relationship between temporomandibular joint dysfunction and psychological distress among students of Babol University of Medical Sciences and Technology, Iran. J Oral Health Oral Epidemiol 2015; 4:94-101.

7. Roger BF et al. Psychological Factors Associated with Development of TMD: the OPPERA Prospective Cohort Study. J Pain 2013; 14.

8. Rollman GB and Gillespie JM. The role of psychosocial factors in temporomandibulardisorders. Curr Rev Pain 2000; 4:71-81.

9. Turner JA, Dworkin SF, Mancl L, Huggins KH, Truelove EL. The roles of beliefs, catastrophizing, and coping in the functioning of patients with temporomandibular disorders. Pain 2001; 92:41.

10. Auerbach SM, Laskin DM, Frantsve LM, Orr T. Depression, pain, exposure to stressful life events, and long-term outcomes in temporomandibular disorder patients. J Oral Maxillofac Surg 2001; 59:628.

\section{Please cite this article in press as:}

Kiren J and Karpagam K (2017), Psychological Distress And Coping Strategies Among Patients With Temporomandibular Disorders (TMDS), International Journal of Current Advanced Research, 6(3), pp. 2673-2675. http://dx.doi.org/10.24327/ijcar.2017. 2675.0073 